This item was submitted to Loughborough's Research Repository by the author.

Items in Figshare are protected by copyright, with all rights reserved, unless otherwise indicated.

\title{
Bonus or burden? Care work, inequality, and job satisfaction in eighteen European countries
}

\author{
PLEASE CITE THE PUBLISHED VERSION
}

PUBLISHER

Oxford University Press (OUP)

VERSION

AM (Accepted Manuscript)

\section{PUBLISHER STATEMENT}

This is a pre-copyedited, author-produced version of an article accepted for publication in European Sociological Review following peer review. The version of record Naomi Lightman, Anthony Kevins, Bonus or Burden? Care Work, Inequality, and Job Satisfaction in Eighteen European Countries, European Sociological Review, 35 (6), pp.825-844 is available online at: https://academic.oup.com/esr/advancearticle/doi/10.1093/esr/jcz032/5521386 and https://doi.org/10.1093/esr/jcz032.

\section{LICENCE}

CC BY-NC-ND 4.0

\section{REPOSITORY RECORD}

Lightman, Naomi, and Anthony Kevins. 2019. "Bonus or Burden? Care Work, Inequality, and Job Satisfaction in Eighteen European Countries". figshare. https://hdl.handle.net/2134/9976268.v1. 


\title{
Bonus or Burden?
}

\section{Care Work, Inequality, and Job Satisfaction in Eighteen European Countries}

\author{
Naomi Lightman, $\mathrm{PhD}$ \\ Assistant Professor \\ Department of Sociology, University of Calgary \\ naomi.lightman@ucalgary.ca \\ naomilightman.wordpress.com \\ Anthony Kevins, $\mathrm{PhD}$ \\ Marie Curie Research Fellow \\ Utrecht University School of Governance \\ a.v.kevins@uu.nl \\ anthonykevins.github.io
}

\section{Published in the European Sociological Review, http://doi.org/10.1093/esr/jcz032}

Abstract: While existing research highlights the feminized and devalued nature of care work, the relationship between care work and job satisfaction has not yet been tested cross-nationally. England (2005) provides two theoretical frameworks that guide our thinking about this potential relationship: the Prisoner of Love framework suggests that, notwithstanding the explicit and implicit costs of care work, the intrinsic benefits of caring provide "psychic income" and lead to greater job satisfaction; while the Commodification of Emotion framework suggests, instead, that care work generates additional stress and/or alienation for the worker, thereby resulting in lower job satisfaction. This article empirically tests this relationship in 18 countries using European Social Survey (ESS) data and incorporating national-level factors. The results provide support for the Prisoner of Love framework, with variation based on the degree of professionalization. Although we find broad evidence of a care work-job satisfaction bonus, non-professional care workers experience a substantively larger bonus than their paraprofessional and professional counterparts. However, national-level economic inequality is also found to play a role in this relationship, with higher inequality amplifying the care work bonus at all levels of professionalization.

Keywords: care work; Europe; gender; inequality; job satisfaction; professionalization; public opinion; stratification 


\section{Introduction}

Care work is both highly gendered and financially and socially undervalued (Budig et al., 2018, Hochschild, 2012). Yet we know surprisingly little about whether, cross-nationally, the unique characteristics of care work impact levels of job satisfaction. In her seminal 2005 article "Emerging Theories of Care Work", England provides two frameworks which help to conceptualize this potential relationship. On the one hand, England outlines the Prisoner of Love framework, which emphasizes that despite the explicit and implicit costs of working in a caring occupation, helping others has intrinsic benefits. According to this framework, care work relies on the altruistic motivations of (typically female) workers and is found, in many cases, to be uniquely rewarding - leading to greater job satisfaction than in comparable non-caring occupations. On the other hand, England details the Commodification of Emotion framework; this suggests that caring occupations, by requiring "deep acting" by workers forced to pretend they care about their clients, increases stress and work alienation. From this perspective, care workers should have lower job satisfaction than individuals in comparable non-caring occupations. Thus, while the relationship between care work and job satisfaction is shaped by both structural conditions and individual relationships between care providers and recipients, England (2005: p. 391) states "one theory sees nonpecuniary amenities and the other disamenities of care work".

The current study uses survey data from 18 European countries to contribute to this debate. Broadly, we investigate whether there is an intrinsic benefit or burden associated with paid work in care and examine how these effects might be shaped by inequality. In so doing, we address several gaps in the existing canon of care work literatures. First, the vast majority of this research is theoretical, qualitative, or focused on a single country; this despite growing recognition of common trends within care work across high- and middle-income countries (Duffy et al., 2013, Hochschild, 2012). Second, our study moves beyond dichotomous measures of care work, suggesting that without disaggregating occupations by their degree of professionalization, important variations end up obscured (Hebson et al., 2015, Lightman, 2017). Third, research on care work tends to focus on national policy differences in care provisioning, or on measuring the 
financial devaluation associated with feminized care work occupations (e.g. An and Peng, 2016, Budig and Misra, 2010). Notwithstanding the importance of these inquiries, crossnational research on care work and job satisfaction has thus far been absent, limiting our ability to compare the theoretical frameworks presented by England. Fourth, and finally, our study is the first to incorporate national-level factors within its methodology, and we pay particular attention to the potential role of national-level economic inequality. While research suggests that inequality diminishes overall job satisfaction (de Bustillo Llorente and Macias, 2005, Pichler and Wallace, 2009), its effects on care work have thus far remained unassessed.

We conduct our analysis using data from the fifth round of the ESS (2010-2013). These data are ideal for our purposes, since they offer the fine-grained occupational information required for our care work measure, alongside multiple items assessing components of job satisfaction. Overall, the investigation demonstrates that care work, occupational professionalization, and national inequality interact to shape job satisfaction. We thus provide empirical support for, as well as add nuance to, the Prisoner of Love framework.

\section{Care Work and Job Satisfaction}

We begin our article with a description of two theoretical frameworks outlined by England (2005). First, the term "prisoner of love", coined by Folbre in her 2001 book, The Invisible Heart, describes a complicated relationship between care work and altruism. The Prisoner of Love framework suggests that, due to various nonpecuniary amenities (e.g. positive emotions, autonomy), care workers express greater job satisfaction than individuals in otherwise similar occupations. This framework is situated within a feminist tradition acknowledging gendered social norms about caring and the reality that women perform the majority of care work (Folbre, 2012). As the term "prisoner" suggests, the commitment to care work is not entirely voluntary, but rather normative, or socially-imposed. Nonetheless, due to gendered roles and expectations, women may become attached to caring jobs and/or be motivated to develop applied skills in caring occupations (Benoit and Hallgrimsdottir, 2011, Palmer and Eveline, 2012). Yet, this framework leaves open the possibility that, over time, the increasing economic and social costs of providing care may lead to greater nonconformity with norms, with a 
resultant decrease in job satisfaction. As Folbre states "increases in the care [wage] penalty, like increases in most penalties, will eventually have a deterrent effect. People will learn to avoid situations in which they might come to care" (2001: p. 41). Scholars who rely on a Prisoner of Love framework typically suggest that care workers gain job satisfaction by developing meaningful relationships with their clients and knowing that they are helping others (Johnson, 2015, Martin-Matthews and Sims-Gould, 2011). However, while numerous studies provide empirical support for this framework (Anderson and Hughes, 2010, Tuominen, 2003, Wharton, 1999), evidence of an ongoing international labour shortage in many caring sectors (e.g. childcare and nursing), along with a growing dependence on women migrating from poorer to richer countries to fill these jobs, suggests that all is not quite so rosy. In a context of low wages and poor job quality, the intrinsic benefits of care work are clearly not sufficient to attract the number of workers needed domestically (Hebson, Rubery and Grimshaw, 2015, Hochschild, 2012).

The Commodification of Emotion framework, by contrast, primarily focuses on negative aspects of care work, yet still acknowledges the context-specific and relational nature of job satisfaction for workers in health and social care. This viewpoint is traced to Hochschild's formative ethnographic research on feminized emotional labour, notably in The Managed Heart (1983). Here, Hochschild analyzes the ways that flight attendants are taught to display feelings they do not actually feel at work, finding that this socialization process leads to emotion-related stress and alienation. Thus, the Commodification of Emotion framework suggests that emotional harm accrues to (typically female) workers when they are required to sell services that use an intimate part of themselves. In turn, the "deep acting" of pretending to care may lead to the development of real caring emotions, as relationships between providers and recipients develop. In either scenario, care work can lead to psychological damage and, as a consequence, lower job satisfaction (England, 2005, England et al., 2012).

Empirical support for the Commodification of Emotion framework is relatively limited, however. Chesters and Baxter (2011) find that Australian childcare workers are less satisfied with their jobs than dental assistants, despite a greater proportion of the former 
providing altruistic reasons for entering the occupation. Yet the authors also find that the most important factors predicting job satisfaction for both groups are day-to-day work experiences. Similarly, much of the literature testing the Commodification of Emotion framework suggests that the relationship between lower job satisfaction and care work is not clear cut (Anderson and Hughes, 2010, Wharton, 1999).

Given the highly feminized composition of care work, its potentially unique relationship with job satisfaction may be influenced by what is termed the "gender-job satisfaction paradox". This literature finds that women, in both full- and part-time employment, consistently report higher levels of job satisfaction than men. Notably, this is despite women's lower returns to human capital and occupational segregation, often hindering both choice of work (e.g. selection into highly feminized caring occupations) and opportunities for advancement (Eurofound, 2006, Sousa-Poza and Sousa-Poza, 2000, Zou, 2015).

While the gender-job satisfaction paradox is often attributed to women's distinct work orientations, either suggesting that women "expect less" than men or that they prioritize work-family adaptations, Grönlund and Öun (2018) present compelling evidence disputing both explanations. Their study finds ongoing evidence of women's higher job satisfaction, even holding human capital investment constant within a context where women's employment is strongly supported by policies, practices, and social norms. Instead, Grönlund and Öun highlight gender socialization and inequities as alternative explanations. Thus, in the case of care workers, it follows that ascriptive characteristics (e.g. gender) as well as workplace conditions and remuneration levels may shape job satisfaction (Hebson, Rubery and Grimshaw, 2015).

In addition to gender's role in shaping job satisfaction, findings from Atkinson and Lucas (2013) suggest that subjective assessments of job satisfaction must be contextualized based on care workers' relative qualification levels. Thus, job satisfaction may be connected to occupational prestige, including across the care/non-care work divide. Existing literature therefore suggests probable variation in job satisfaction across different types of care work, relating to differing qualifying requirements and associated social value and remuneration levels (c.f. Barron and West, 2013, Lightman, 2017, Magnusson, 2008). 


\section{Care Work Cross-Nationally}

Increasingly, care work is conceptualized within a globalized, transnational labour market (Hochschild, 2012, Parreñas, 2016). Typically, such studies examine national policy differences in care provisioning and/or aim to quantify any care work wage penalties (An and Peng, 2016, Budig, Hodges and England, 2018). Cross-national research on job satisfaction and care work, by contrast, has so far been absent. Partly as a consequence, the ways that national conditions may interact with care work to influence attitudes has been undertheorized. Although various factors might shape this relationship - such as GDP, unemployment rates, and welfare state provisions (Kjeldsen and Bøgh Andersen, 2013, Pichler and Wallace, 2009) - our focus is on a single factor that has received particular attention in recent years: economic inequality (e.g. Kevins et al., 2018, Schröder, 2016, Wilkinson and Pickett, 2010).

Previous studies have demonstrated that macro-level economic inequality not only leads to poorer health and lower levels of trust and social mobility, but also shapes comparisons with referent others, with greater perceived differences leading to overall lower levels of job satisfaction (de Bustillo Llorente and Macias, 2005, Jiang and Probst, 2017). As inequality increases, pay differences grow - even among roughly similar jobs and dissatisfaction is a likely outcome: "Put simply, perceived 'unfairness' could make people dissatisfied with their jobs. In a more equal society, however, perceptions of differences could be less likely despite having dissimilar job duties, differences in pay, and so forth" (Pichler and Wallace, 2009: p. 539).

Existing studies do not, however, account for the ways that inequality may matter differently in and out of care work. It is possible that any care work bonus or burden may be amplified in highly unequal countries; this is because the "psychic income" or, conversely, emotional burnout, distinctive to care work jobs may take on added significance when levels of job satisfaction are lower and status anxiety concerns are greater (e.g. Delhey and Dragolov, 2013, Layte and Whelan, 2014). Yet it is equally conceivable that the opposite might be true: that at lower levels of inequality, differences between jobs become more qualitative in nature, thereby increasing the relative importance of any care work bonus or burden. Either way, given that inequality shifts the 
relative status and job satisfaction of professionals and non-professionals in different ways, we expect that this effect may also vary across levels of professionalization in care work. In sum, we suggest that there are good reasons to believe that inequality may interact with individual-level characteristics to shape job satisfaction across the care/noncare work divide, regardless of whether greater evidence is found for the Prisoner of Love or Commodification of Emotion framework.

\section{Classifying Care Work}

In order to evaluate the impact of care work on job satisfaction, the concept must first be defined and operationalized. Existing care work scholarship is nevertheless divided as to how this is best done. Two key axes of differentiation distinguish between the inclusion of (1) direct versus indirect care provision and (2) professional versus paraprofessional or non-professionalized occupations. Thus, varying definitions of care work operationalize care providers to include or exclude people in a range of occupations and with divergent social statuses.

To begin, there is debate as to how to parse direct versus indirect care work distinctions. Direct care work (also termed "nurturant care work" and "interactive care work") is typically defined as employment that involves face-to-face, personal interactions with children, the elderly, or people with complex healthcare needs (England et al., 2002, Folbre, 2012). By contrast, indirect care work (also termed "reproductive labour" and "care support work") is commonly conceptualized as providing auxiliary support for those providing direct care. Presently, scholars are divided on the inclusion of indirect care work within their care classification schemes.

Dwyer (2013) suggests that teachers, clergy, therapists, and postsecondary instructors can be conceptualized as engaging in "nurturant" direct care work, while indirect "reproductive labourers" (e.g. housekeepers, barbers, and laundry workers) typically support operations of daily life. However, other scholars note that there is not a clear dichotomy between direct and indirect care. Lutz (2012), for example, states that it is difficult to disentangle the overlapping of care or domestic services in daily practices, while Anderson and Hughes (2010) argue that certain caring occupations encompass both 
direct and indirect care simultaneously (e.g. live-in nannies, personal care assistants for the elderly).

Beyond the direct/indirect care work distinction, critical differences in the literature lie between those who conceptualize care in broader or narrower fashions. For those authors who subscribe to a narrow definition of care work, the focus is most often exclusively on low-status (female) workers, primarily in health and childcare, such as day care assistants and home health aides (e.g. Gerstenblatt et al., 2014, Lowell et al., 2010).

However, other definitions of care work are far broader. England et. al (2002), for example, operationalize care work to include both regulated and unregulated occupations that provide a service that helps “develop [people's] capabilities". This includes childcare, teachers (from preschool to university), healthcare workers (from nurses' aides to doctors), and individuals in the "helping professions" (e.g. therapists, social workers, clergy). Care work by this definition therefore includes individuals with very low status (or occupational prestige) as well as those with very high status (and often concomitant professional qualifications and salaries). Indeed, partly out of a need for appropriate sample sizes, most quantitative comparative research on the topic takes this broader approach to defining care work (e.g. Budig and Misra, 2010, Lightman, 2018).

Following England et. al's (2002) formative example, we develop and apply a unique care work classification scheme for use with the 2010 ESS. Our aim is to examine variation in job satisfaction in 18 countries, distinguishing care workers by their degree of occupational professionalization: we thus compare the job satisfaction of professional, paraprofessional and non-professional jobs in and out of care work.

Our focus is broadly on caring jobs in health, education, and social work. Given the importance accorded to low-status care work within the relevant literature, we include indirect caring occupations in the field of personal services (e.g. hairdressers and domestic housekeepers) in our classification scheme. This allows us to examine the job satisfaction of care workers at varying levels of professionalization, while simultaneously increasing our sample of care workers.

Intentionally, our three groups of care occupations have variable wages, attendant social status, and levels of feminization. The categories are: 1) Professional occupations in 
care, e.g. medical doctors, nursing professionals, university professors, secondary school teachers, and social work professionals; 2) Paraprofessionals in care work, e.g. medical assistants, nursing and midwifery paraprofessionals, pre-primary education teaching paraprofessionals, and social work paraprofessionals; and 3) Service occupations in care, e.g. institution- and home-based personal care workers, childcare workers, domestic housekeepers, hairdressers, and cooks. Our analysis then investigates the relative job satisfaction of care workers and non-care workers at each level of professionalization.

Figure 1: Percentage of female workers by professionalization level, in and out of care work

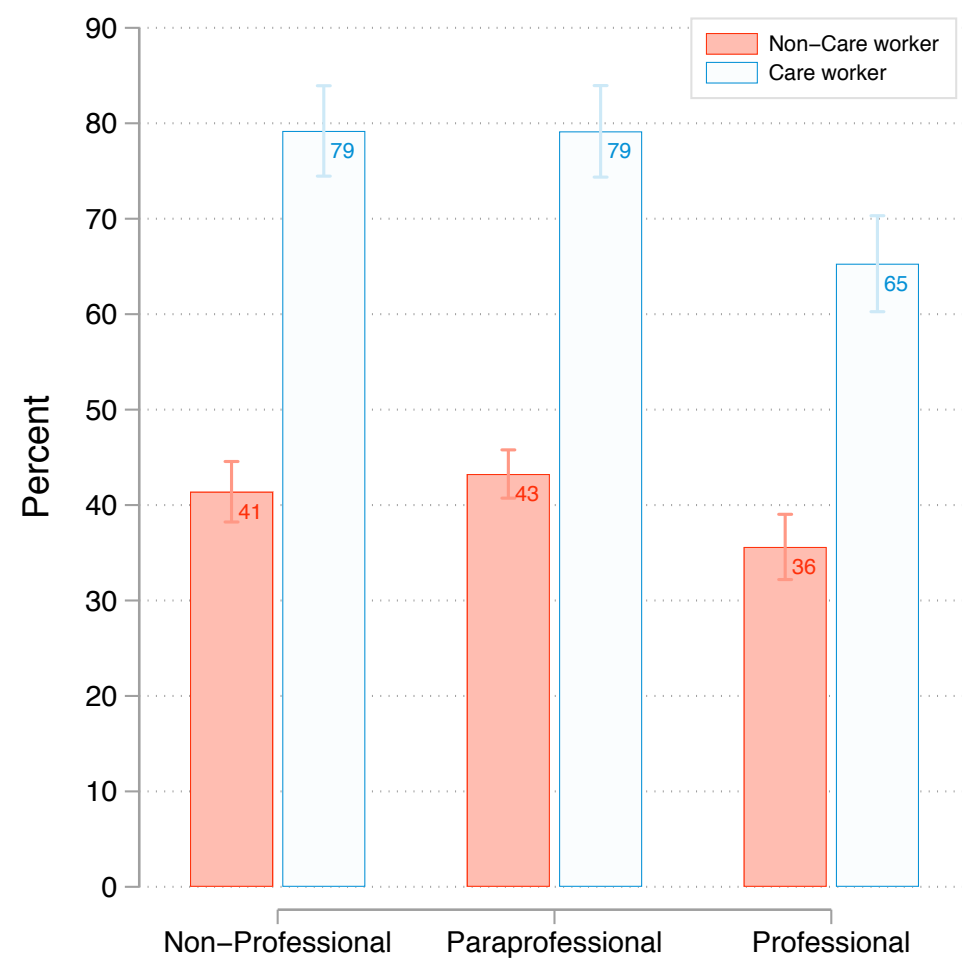

Figure 1 provides a breakdown of the gender composition at each level of professionalization, illustrating the percentage of females in each category, both in the care sector and outside of it (incorporating survey weights and illustrating 95 percent confidence intervals). The data demonstrate that all types of care work are highly feminized. However, as anticipated, professional care workers are the least skewed of the groups (at 65 percent female), while nearly four out of five paraprofessional and non- 
professional jobs in care are performed by women (at 79 percent female) crossnationally.

\section{Hypotheses}

Connecting the theoretical and empirical literatures on care work, job satisfaction, occupational professionalization, and economic inequality leads us to develop the following five hypotheses. At the most basic level, we seek to distinguish between England's two theories on the relationship between job satisfaction and care work: first, the Prisoner of Love framework suggests that there will be a positive association between care work and job satisfaction, due to the intrinsic rewards of caring (H1); second, and by contrast, the Commodification of Emotion framework suggests that there will be a negative relationship between care work and job satisfaction, given the psychological damage and stress inherent in these jobs (H2).

At the same time, we believe that these two frameworks view care work in overly simplistic terms, lumping together very different types of care workers. In particular, it is not obvious that professional care workers would benefit from providing care as a "compensating differential", as they are already engaged in relatively high-status, highincome employment. Thus, while non-professional care workers may rely on the nonpecuniary benefits of care work to compensate for their lower relative status, professional care workers may be more likely to either (a) be unaffected by any distinctive quality of care work or (b) be more affected by the negative implications of care work. Adding nuance to the above two hypotheses ( $\mathrm{H} 1$ and $\mathrm{H} 2)$, we therefore expect that professional care workers will be less likely to benefit from a care work bonus than their non-professional counterparts (H3).

Finally, we suggest that the relationship between job satisfaction and care work may also vary based on national-level economic inequality. On the one hand, inequality might exacerbate any care work burden or bonus: as inequality - and the associated health and social challenges within society - increase, so too may the factors generating care burdens (i.e. stress, alienation) or bonuses (i.e. compensating differentials). From this perspective, we would expect that, regardless of the direction of any care effect, higher 
levels of inequality will amplify its impact (H4a). Yet the opposite might also be true: the impact of a care work burden or bonus on job satisfaction may be greater at lower levels of inequality (H4b), as low wage differentials may increase the relative importance of qualitative, non-pecuniary differences among jobs.

However, this amplifying effect may also vary in strength based on the level of professionalization of the care worker, as inequality will influence their economic circumstances and social status in opposite ways (e.g. professionals will see their relative income increase, while non-professionals will see it decrease). We thus hypothesize that the effect of national inequality on any potential care work bonus or burden will vary based on the professionalization level of the worker (H5).

\section{Data}

Our analysis is based on the fifth round of the European Social Survey (ESS, 2010), which was fielded between 2010 and 2013 using face-to-face interviews. While the ESS is a multi-wave survey, the fifth round is ideal for our purposes as it contained a special module on "Work, Family, and Wellbeing". ${ }^{1}$ The questions contained in this module allow us to construct a measure of job satisfaction based on a range of relevant metrics.

Our study focuses on 18 European countries, with the cases selected based on data availability; we exclude countries for which national-level controls are unavailable, as well as those with a particularly small number of respondents with recorded occupational codes. We restrict our sample to respondents who are (1) working age (defined here as between 18 and 70 years), (2) employed, and (3) located outside of the military and primary sectors of the economy (i.e. agriculture, forestry, and fisheries). ${ }^{2}$ After accounting for missing data, our analysis includes 9917 respondents, with per-country samples ranging from 268 in Slovenia to 955 in Germany (see Figure 2 below for further details).

\section{Dependent Variable}

To analyse job satisfaction, we constructed an index using seven questions from the "Work, Family, and Wellbeing" ESS module. These questions address different components of job satisfaction ${ }^{3}$ and are worded as follows: 
- Support: "I can get support and help from my co-workers when needed"

-Advancement: "My opportunities for advancement are good"

- Pay: "Considering all my efforts and achievements in my job, I feel I get paid appropriately"

-Variety of tasks: "There is a lot of variety in my work"

- Job security: "My job is secure"

- Job enjoyment: "I would enjoy working in my current job even if I did not need the money"

-Overall satisfaction: "How satisfied are you in your main job?"

The range of available responses to these questions varies, but each ultimately aims to assess agreement: the responses to Support, Variety of tasks, and Job security range from 1 "Not at all true" to 4 "Very true"; the Advancement, Pay, and Job enjoyment responses are recorded on a five-point scale ranging from 1 "Agree strongly" to 5 "Disagree strongly"; and Overall satisfaction is recorded on a scale ranging from 0 "Extremely dissatisfied" to 10 "Extremely satisfied". (Note that all questions also include a "Don't know" response option, coded as missing.)

We then used Item Response Theory (IRT) to build an index based upon these seven questions (after recoding responses such that higher numbers indicate greater satisfaction). IRT allows us to assess a latent trait while also accounting for the ordinal nature of the data (see, for example, Treier and Hillygus, 2009). (Note that conventional factor analysis, with its assumption that responses are distributed normally, would thus be inappropriate.) The resulting job satisfaction index ranges from -3.39 to 2.54 , with a weighted mean of 0 and a standard deviation of 0.85 .

This multi-item approach has various benefits over relying solely on the Overall satisfaction question (see Hebson, Rubery and Grimshaw, 2015). First, doing so allows us to be specific about which workplace factors are incorporated into the measure; by contrast, the Overall satisfaction question incorporates a variety of different job facets that vary across individuals (D’Addio et al., 2007). Most importantly, however, responses to the Overall satisfaction question are heavily skewed toward "satisfaction," with only 
$7 \%$ of all respondents expressing any dissatisfaction whatsoever (and less than $0.5 \%$ stating they were extremely dissatisfied). This also accords with Rose (2003) and Mittal et al. (2009), who suggest that individuals substantially overstate their job satisfaction when only a single measure is used (doing so to avoid an internal admission of a lack of marketable skills, initiative and/or capacity to change jobs, or as a means to "post hoc" rationalize their acceptance of low wages).

As a result of the skewed nature of the single-item measure, recent studies using job satisfaction as a dependent variable tend to either opt for an index (Grönlund and Öun, 2018, McPhail et al., 2015) or to create cut-offs and then place respondents into one of 23 groups (Hauret and Williams, 2017, Viñas-Bardolet et al., 2018). As the latter necessarily entails choosing relatively arbitrary cut off points, we opt for the index in this analysis (see also Eurofound, 2006). We nevertheless confirm the robustness of the results by altering our dependent variable in sensitivity analyses.

\section{Independent Variables}

Our research focuses on the potential relevance of care work as a determinant of job satisfaction, considered in tandem with level of professionalization. We therefore classified respondents along these two dimensions using their recorded International Standard Classification of Occupations (ISCO-88) codes. In doing so, we divided occupations between those that are in and out of care work, and then parsed both caring and non-caring occupations into professional, paraprofessional, and non-professional categories. (Our full care work classification scheme is found in Appendix Table 1.) By interacting the care work and professionalization variables in the analysis below, we can account not only for the potential relevance of care work on job satisfaction, but also for variation based on level of professionalization.

Categorizing respondents in this way results in a sample in which, as anticipated, a minority of respondents are employed in some sort of care work (at 22\%), while most workers are either found in paraprofessional (at 43\%) or non-professional (at 30\%) occupations. Care workers, by contrast, are more likely to be engaged in either professional (at 38\%) or non-professional (at 34\%) occupations. Patterns nevertheless vary considerably by country, as illustrated in Figure 2. 
Figure 2: Percentage breakdown of care and non-care occupational groups, by country

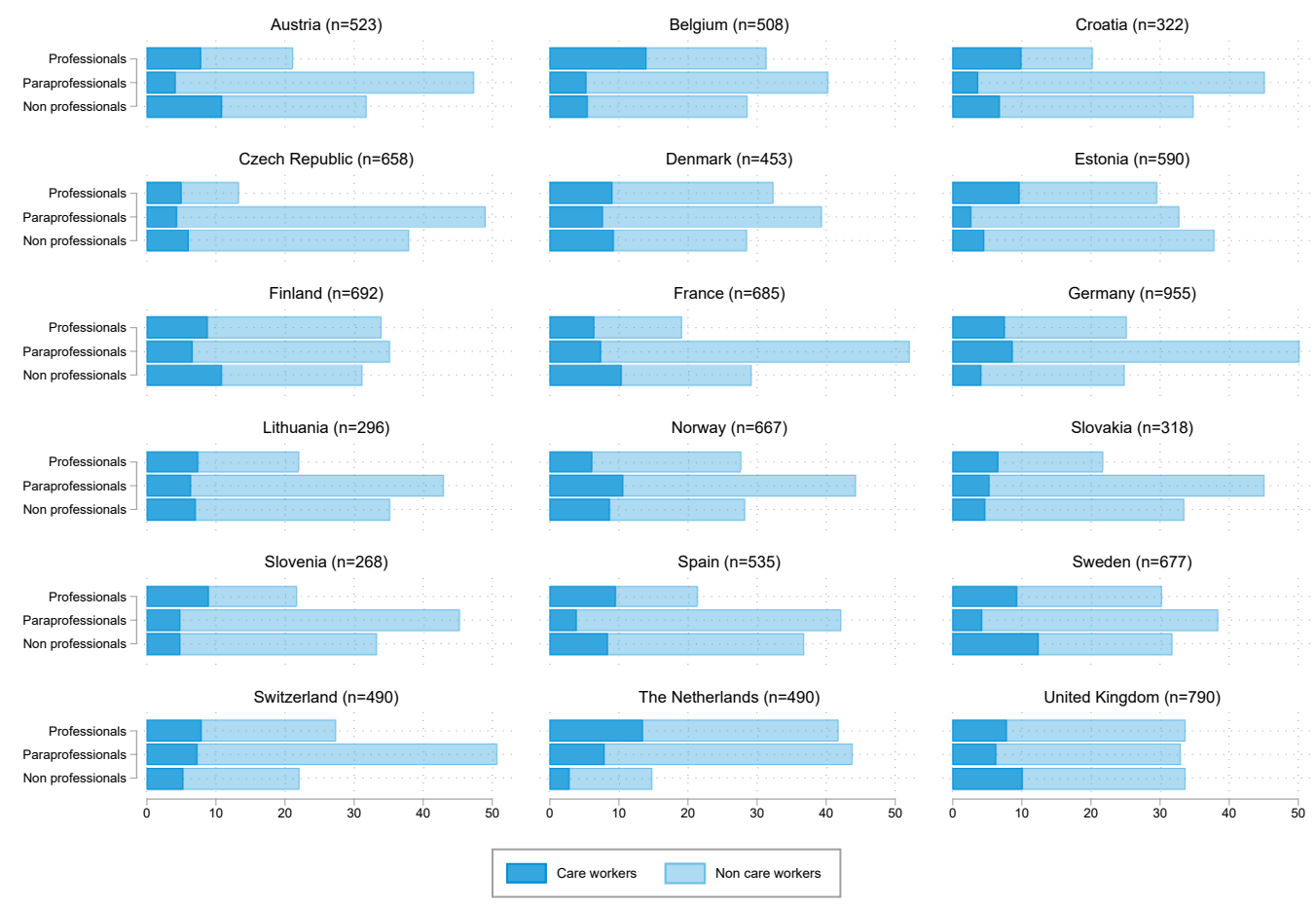

In addition to examining the effects of different types of care work, we include a series of potentially relevant control variables, building from past studies on job satisfaction (e.g. Grönlund and Öun, 2018, Hauret and Williams, 2017). At the individual-level, we include a wide range of demographic variables, namely: gender (males coded as 1, females as 0 ); (self-described) minority status; immigrant status; age and its square, to allow for non-linear effects; education level (using the five-category harmonized ISCED97 scheme); marital status (with respondents who are married or in common-law relationships coded as 1); as well as household income decile (with brackets reflecting national decile divisions) and household size. In addition, we include several binary controls tied to employment status. We account for: trade-union membership; employment in the public sector; holding a supervisory position; self-employment; parttime employment; and working a fixed-term contract.

As our intention is also to incorporate national-level variation, we subsequently interact the care work and degree of professionalization variables with inequality, as measured by the Gini coefficient. Gini scores (from Eurostat) are based on the distribution of 
household income, adjusted to account for household size. Our full models incorporate a three-way interaction between care work, level of professionalization, economic inequality, and a series of individual- and national-level controls.

Figure 3: Mean inequality and job satisfaction by country, across occupational groups
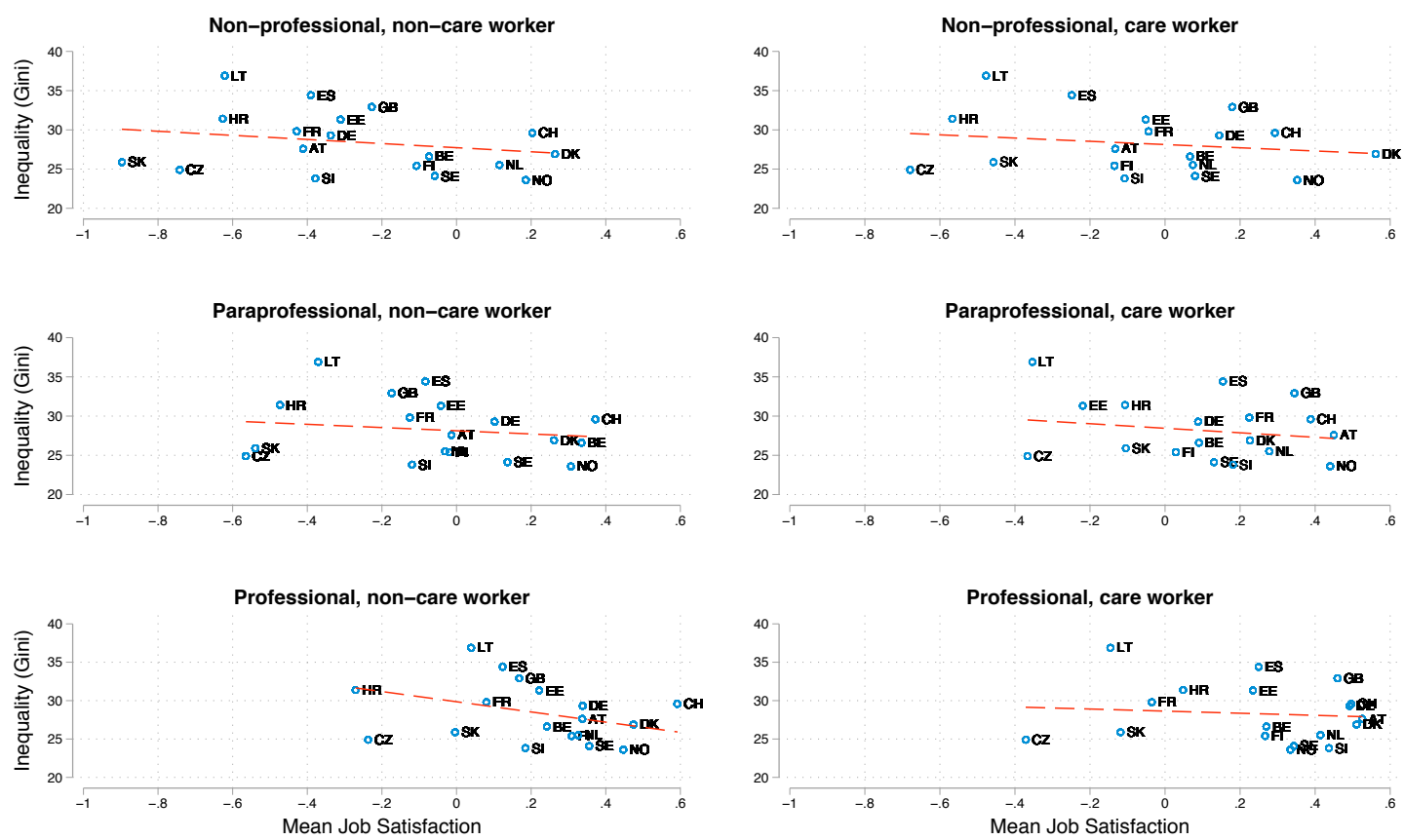

Country $\quad-\quad-$ Line of best fit

To provide some initial insight into what this relationship might look like, Figure 3 breaks down the sample into the six occupational categories (i.e. along the care work and professionalization divisions). Each of the six panels represents one of these respondent groups, with countries plotted according to their level of inequality and the mean level of job satisfaction within that subsample. The line of best fit is then added to highlight the bivariate relationship between inequality and mean job satisfaction for each respondent group. These preliminary results suggest that: (1) level of professionalization is positively related to job satisfaction, with individuals employed in non-professional employment (both caring and non-caring) less satisfied on average - likely due, in part, to their comparatively low wages and social status; (2) non-professional and paraprofessional care workers are generally more satisfied than their non-care work equivalents; and (3) 
job satisfaction appears, overall, to be negatively affected by higher levels of inequality, but the size of that effect varies by subgroup - most evidently, we note markedly different trend lines for professionals inside and outside of work in care.

We thus anticipate that there may be something distinct about care work at all levels of professionalization when it comes to the relationship between inequality and job satisfaction. Without any controls in the analysis, however, Figure 3 only provides initial evidence to suggest that inequality matters.

Our multivariate analysis adds not only the individual-level controls referenced above, but also several standard national-level ones chosen for their connection to the labour market (in addition to our focal variable, economic inequality). These controls are: the national unemployment rate and the natural log of per capita GDP (both taken from Eurostat). With only 18 countries, we restrict the number of national-level controls in order to reflect the limited degrees of freedom - but as various other contextual factors might matter, we also ensure that our key findings below are robust to changes in the included controls (e.g. using other GDP measures, adding an Eastern European binary control, or including levels of social expenditure as a percentage of GDP). Note also that the relatively low number of countries in our multi-level models may also bias our estimates of country-level effects; given the size of our country samples, however, this issue should have a limited impact on estimates of cross-level interaction effects - the focus of our attention here (see Mathieu et al., 2012).

Appendix Table 2 provides an overview of each of our individual- and national-level variables. Variance inflation factor scores, in turn, confirm that multicollinearity does not pose a problem, at either the individual- or national-level, with all values below three.

\section{Analysis}

To test our hypotheses, the data analysis proceeds in two steps. First, we construct individual-level only (generalized least squares) models with country fixed effects; in doing so, we build the models stepwise, so as to ensure that our key results are not simply artefacts tied to including a particular set of controls (see Appendix Table 3). We then proceed to the full multi-level model analysis, adding country-level variables to the 
models (once again in a stepwise fashion). Here we employ maximum likelihood estimation and incorporate survey weights, with respondents nested hierarchically in country clusters (see Appendix Table 4). We then conduct a series of robustness checks in order to confirm our key findings (see Appendix Table 5). For ease of interpretation, we illustrate the key results of our analyses via figures, with the full regression tables relegated to the appendices. ${ }^{4}$

Figure 4: Predicted marginal effects of care work employment on job satisfaction (Panel A) and predicted values of job satisfaction for care workers and non-care workers (Panel $B)$, individual-level model
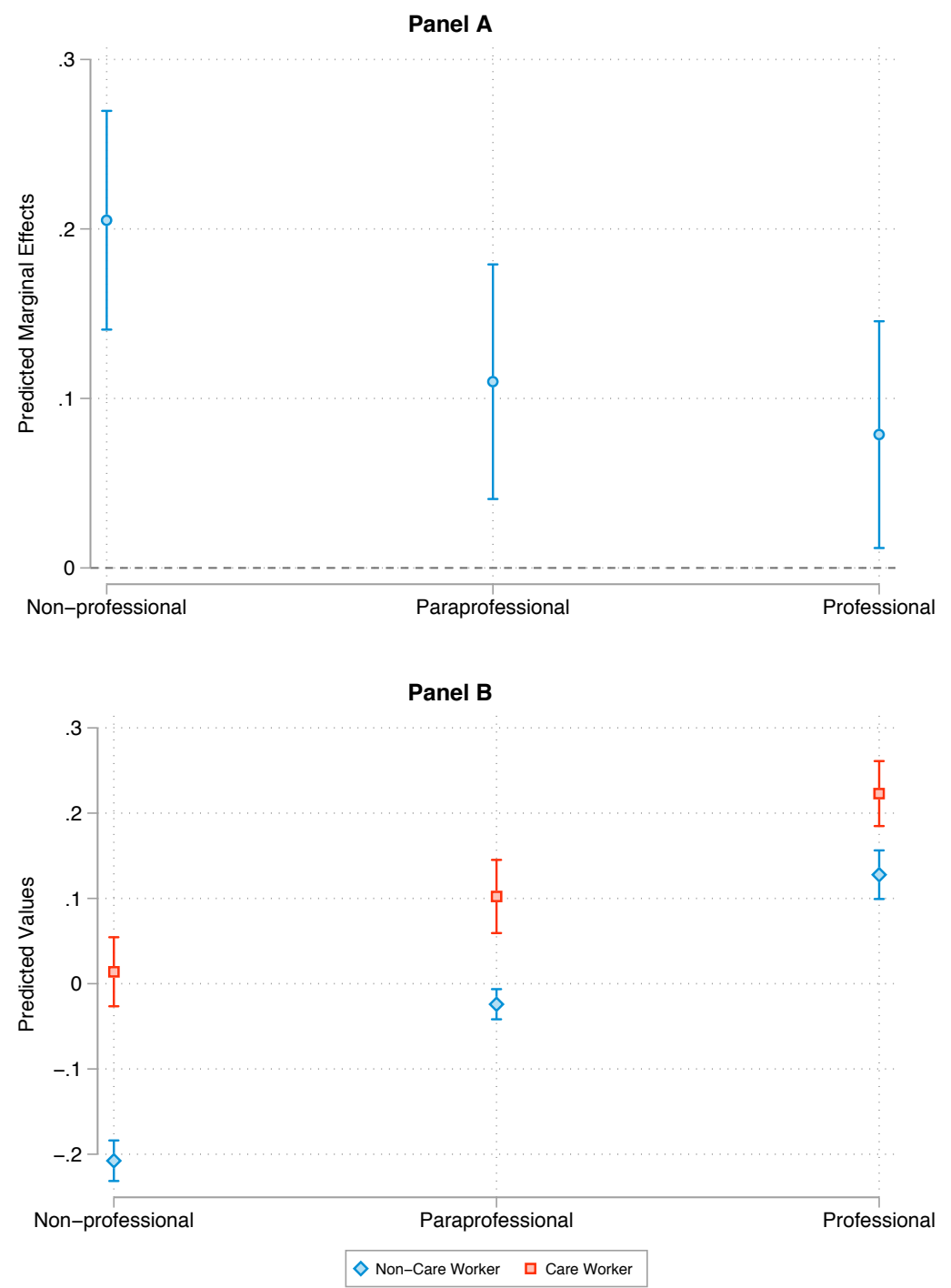
Our analysis begins with a focus solely on individual-level factors, as we aim to uncover any initial evidence that care work and professionalization might interact to shape job satisfaction. To that end, Panel A of Figure 4 presents the predicted marginal effects with 95 percent confidence intervals (using the full model from Appendix Table 3 and holding all other variables at their means) of care work employment for non-professionals, paraprofessionals, and professionals. ${ }^{5}$ This figure demonstrates the average difference between the job satisfaction levels of care workers and non-care workers at each of our three levels of professionalization. (Note that a marginal effect of 0 would indicate no difference from non-care workers.) The figure illustrates that care work has the largest impact on job satisfaction among non-professionals - suggesting that the nonpecuniary benefits of caring are strongest in scenarios of relatively low wages - with a care work bonus of about 0.21 on the job satisfaction index. Yet we also find evidence of a similar, positive effect for both paraprofessional and professional care workers. However, this "bonus" is considerably smaller for these groups, at 0.11 for paraprofessionals and 0.08 for professionals. Tying these results back to our hypotheses, we thus find evidence of $\mathrm{H} 1$ and $\mathrm{H} 3$, but no evidence to support $\mathrm{H} 2$. While there does not appear to be a care work burden, the size of the care work bonus is approximately half as large at higher levels of occupational professionalization.

Panel B in Figure 4 uses the same model to lay out the predicted job satisfaction of care workers and non-care workers at each level of professionalization (once again holding all other variables at their means). Predicted job satisfaction values are demarcated with a square for care workers and a diamond for non-care workers, while 83.5 percent confidence intervals allow us to visualize any predicted value overlap at the 95 percent confidence level (see Bolsen and Thornton, 2014). Thus, the figure plots average levels of job satisfaction across our six groups, highlighting that higher professionalization is positively correlated to job satisfaction on the whole. In addition, the panel illustrates that the professionalization "premium" is smaller for care workers than for those outside of the caring sector.

Having established that care work and professionalization interact to shape job satisfaction, we now turn to examine how national-level characteristics may also play a role. As mentioned above, our final hypotheses (H4a, H4b, and H5) focus on the three- 
way interaction between care work, level of professionalization, and inequality (as measured by the Gini coefficient, with higher values representing greater economic inequality). Appendix Table 4 provides the details of the regression results. ${ }^{6}$

Figure 5 presents the key results from this analysis, demonstrating the relationship between care work, professionalization, and inequality vis-à-vis job satisfaction. The three panels show the predicted marginal effect of being in care work, broken down by level of professionalization and illustrated across a truncated range of inequality values (excluding extreme Gini coefficient values at the bottom and top ten percent of our sample).

Figure 5: Predicted marginal effects of care work employment on job satisfaction, by inequality
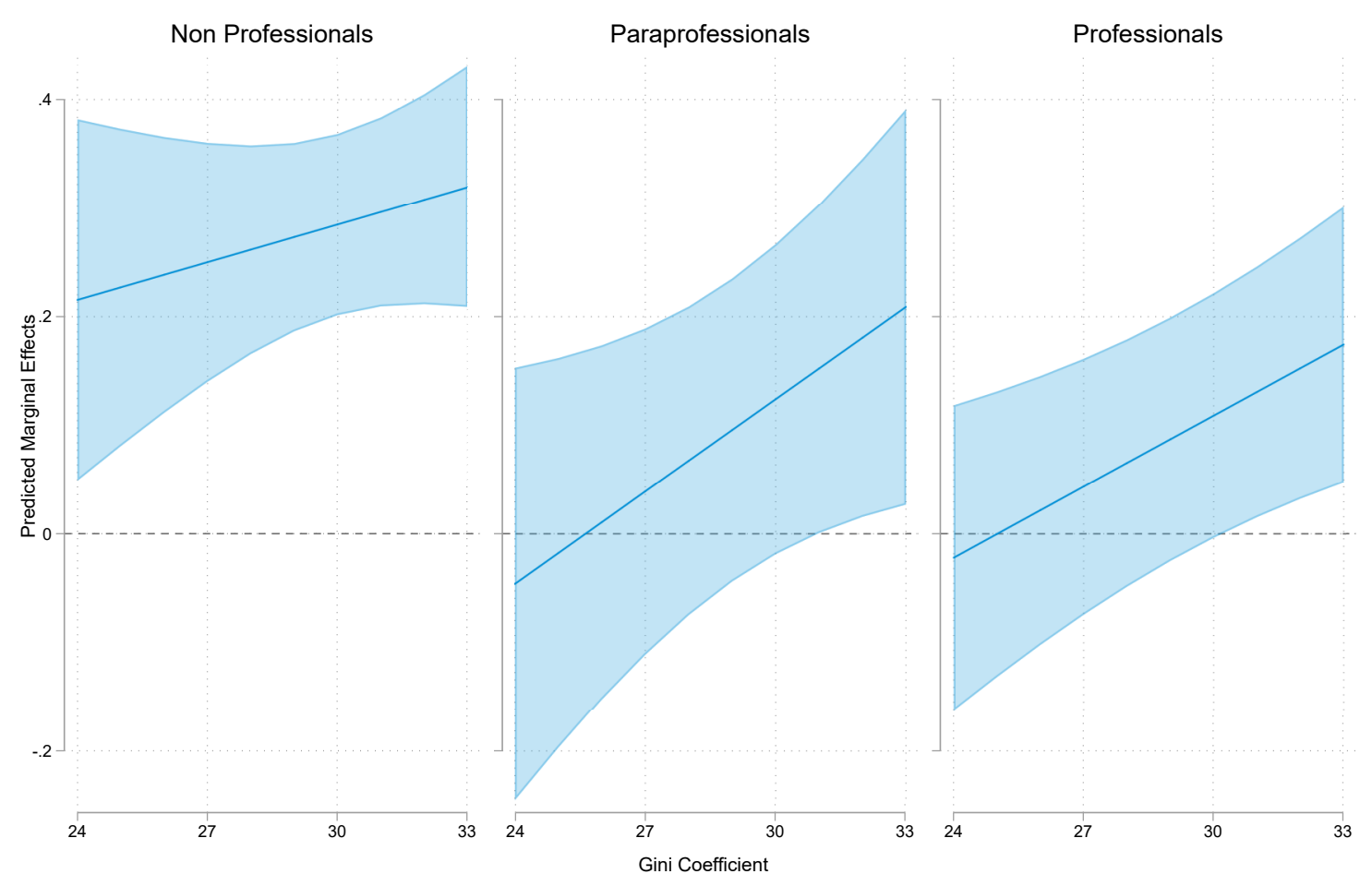

In line with the findings of the individual-level model, we once again see that care work is associated with a (varyingly-sized) job satisfaction bonus across all three levels of professionalization. Yet, interacting the professionalization and care work variables with 
the Gini coefficient values also suggests that inequality shapes the impact of the care work bonus, and that it does so in two distinct ways.

On the one hand, higher levels of inequality are generally associated with larger care work bonuses: as we move from the $10^{\text {th }}$ to the $90^{\text {th }}$ percentile of inequality levels, the size of the care bonus increases by 0.10 among non-professionals, 0.25 among paraprofessionals, and 0.19 among professionals. Yet we also see that the care work bonus for paraprofessionals and professionals appears to be limited to countries with relatively high inequality. At Gini coefficients below about 30 (for paraprofessionals) and 31 (for professionals), the size of the care work bonus becomes statistically indistinguishable from zero. Concretely, this suggests that, when holding all other variables at their mean, the care work bonus is absent for paraprofessionals and professionals in five of our eighteen countries (namely, Estonia, Croatia, Latvia, Spain, and the United Kingdom).

These findings thus align with $\mathrm{H} 4 \mathrm{a}$, as the size of care work bonuses increases across all levels of professionalization as inequality goes up. Contrary to H5, however, the size of the care work bonus does not increase disproportionately among non-professionals: although we do note slight differences in the extent to which inequality amplifies the care work bonus across different levels of professionalization (as illustrated by the varying slopes in Figure 5), there is no evidence of a stronger effect among non-professionals. Finally, we conduct a series of robustness checks to confirm our key results (see Appendix Table 5). For the individual-level only analysis, survey weights were excluded from the regression results due to technical limitations with the fixed-effects models; we therefore used ordinary least squares regressions with country dummies to verify that results were unaffected by incorporating survey weights (Appendix Table 5, Model 1). For the full multi-level model analysis, we also confirm that results are robust to incorporating cluster robust standard errors (Appendix Table 5, Model 2) and allowing the slopes for the professionalization and care work variables to vary by country (i.e. random slopes) (Appendix Table 5, Model 3). Key findings remained unaffected in all instances. $^{7}$ 


\section{Conclusions}

This article has examined the relationship between care work, inequality, and job satisfaction in 18 European countries. In doing so, we built from two formative frameworks presented by England (2005) to conceptualize how care work might impact job satisfaction: on the one hand, the Prisoner of Love framework highlights the intrinsic benefits to working in care - suggesting that care workers should have higher levels of job satisfaction; while on the other hand, the Commodification of Emotion framework emphasizes that care workers experience additional stress and/or alienation than otherwise comparable workers - suggesting that care workers should have lower levels of job satisfaction.

As we argued, however, there are good reasons to believe that any such effects differ according to professionalization levels; in particular, we would expect to find considerable variation in the norms, expectations, and previous work experiences of individuals with varying levels of skill and financial remuneration (e.g. any care work bonus or burden should manifest differently for a medical doctor versus a personal support worker). Thus, our analysis disaggregated caring and non-caring jobs into nonprofessional, paraprofessional, and professional categories, and then examined the effect of care work across these different groups. Finally, we incorporated national-level factors into our analysis, exploring the potential role of economic inequality in shaping the relationship between care work and job satisfaction.

Our findings ultimately support the Prisoner of Love framework. While all care work jobs are disproportionately performed by women, our individual-level model finds that care workers have greater job satisfaction than equivalent workers outside of care work, suggesting that the nonpecuniary benefits of caring matter. Note, crucially, that these effects are present even controlling for various key individual-level factors (e.g. gender, income). The size of this care work bonus, however, varies substantially across level of professionalization, with the strongest effects found for non-professional workers. In a sector marked by lower wages, reduced benefits, and weaker employment stability, nonprofessional care workers thus appear to benefit more than their professional or paraprofessional counterparts from the compensating differential provided by "helping 
others" or building relationships with clients. As levels of job satisfaction are generally lower among non-professionals, this finding may also help to explain the gender-job satisfaction paradox, given the disproportionate representation of women within lower status care work jobs.

In addition, our analysis takes into account the turn toward conceptualizing care work within a transnational labour market, incorporating country-level variables into our analysis. In particular, we focus on national inequality, which is broadly associated with decreased job satisfaction. Further nuancing the Prisoner of Love framework, we find that in addition to level of professionalization, economic inequality also impacts the relationship between care work and job satisfaction: specifically, as economic inequality increases, so too does the size of the "care bonus". Contrary to our expectations, however, this amplifying effect appears to be just as strong across all levels of professionalization. Thus, in more unequal countries, where associated harms to health, well-being, and social harmony are well documented, care workers tend to be more satisfied with their jobs than comparable individuals outside of the care sector. The care work bonus, then, is shaped not only by micro-level factors (such as worker professionalization) but also by macro-level factors (such as inequality) - a finding which underlines the importance of incorporating both individual- and context-related factors when conceptualizing and measuring care work.

Overall, our analyses support and add nuance to England's Prisoner of Love framework. Yet we note several limitations to our study. First, unlike in-depth qualitative studies, our quantitative analyses cannot precisely capture the lived day-to-day work experiences of care workers. Second, despite the likely relevance of country of origin, the number of immigrants in our sample is too small to examine potential differences in job satisfaction between foreign- and native-born care workers. Third, as our analysis already includes a three-way interaction between care work, professionalization levels, and inequality, methodological limitations prevent us from considering the potential interactive role of gender as well. Finally, our care classificaton scheme does not account for variations in the types of indirect versus direct care work done by professional, paraprofessional, and non-professional workers. 
Nonetheless, the results of this study contribute to the growing canon of quantitative and cross-national research on care work, presenting the first large-scale, cross-national analysis of care work and job satisfaction. Findings suggest that the job satisfaction of care workers needs to be carefully contextualized, with divergent satisfaction based on degree of occupational professionalization and heightened care work bonuses in contexts of higher national inequality. This, in turn, invites future research oriented toward uncovering potential divergence in attitudes amongst care workers due to other pertinent social factors such as gender, race, immigrant status, and - crucially - their intersections.

\section{Acknowledgements}

The authors would like to thank Professor Jean Wallace for her helpful comments on an early draft of this paper, as well as the three anonymous reviewers. This work was supported by Naomi Lightman's Social Sciences and Humanities Research Council of Canada Insight Development Grant (File no: 430-2018-00062). Anthony Kevins also received financial support from a Marie Skłodowska-Curie Individual Fellowship (Grant no. 750556). 


\section{Notes}

${ }^{1}$ Although the 2004 round also includes this module, it lacks a standardized income measure. Given the major potential impact of income on job satisfaction, we limit our analysis to the fifth round of the ESS.

${ }^{2}$ As some scholars (e.g. Gerstenblatt et al., 2014) have suggested that healthcare may be distinct from other care fields, we confirm that our results are consistent even when healthcare workers are excluded from the sample.

${ }^{3}$ Other scholars include similar component measures in their job satisfaction indices, including both subjective evaluations of work and asessments of multiple aspects of job quality - such as salary, working hours, and physical and psychological work environment (see Grönlund and Öun, 2018; McPhail et al., 2015).

${ }^{4}$ All figures drawn using "plotplain” (Bischof, 2017).

${ }^{5}$ In Appendix Table 3, Model 1 includes only the care work and level of professionalism variables, Model 2 adds their interaction, Model 3 incorporates standard demographic controls, and Model 4 is the full model, with all labour market and demographic variables included. Key here is the interaction between care work and professionalism, which should be read as follows: the care worker coefficient indicates the impact of care work where professionalism is set to its baseline value (i.e. professionals); the non-professional and paraprofessional coefficients show the difference in job satisfaction between each of these groups and professionals, where care work is set to its baseline value (i.e. non-care workers); and the coefficients for the interactions provide the remainder of the effects.

${ }^{6}$ In Appendix Table 4, Model 1 contains only the three-way interaction; Model 2 adds all individual-level controls; Model 3 introduces a control for the unemployment rate; and Model 4, the full model, also incorporates GDP. We centre the Gini coefficient variable around its mean to improve the interpretability of the table (as no country has a Gini coefficient of zero). Note that we decentre the Gini coefficients in the corresponding figure, however, with results drawn using the full model.

${ }^{7}$ To further investigate robustness, we also re-ran each of our models with varying sets of included variables. These additional tests included: ensuring that alternative nationallevel controls have no effects on our overall results (namely, using other GDP measures, adding an Eastern European binary control, and including a control for social expenditure as a percentage of GDP); and confirming the consistency of our findings across different measures of job satisfaction (namely, a single-item measure looking only at overall satisfaction and a multi-item measure that excludes job enjoyment). Most of our results are robust to these changes, with two exceptions: if we exclude job enjoyment from the index, the interaction between care work and inequality for paraprofessionals only nears significance at best $(\mathrm{p}=0.1)$; and the care work effect among professionals drops out at the individual-level (for the single-item measure) and in interaction with inequality (for both alternative measures). 


\section{References}

An, M. Y. and Peng, I. (2016). Diverging Paths? A Comparative Look at Childcare Policies in Japan, South Korea and Taiwan. Social Policy \& Administration, 50, $540-558$.

Anderson, N. and Hughes, K. D. (2010). The Business of Caring: Women's SelfEmployment and the Marketization of Care. Gender, Work \& Organization, 17, 381-405.

Atkinson, C. and Lucas, R. (2013). Worker responses to HR practice in adult social care in England. Human Resource Management Journal, 23, 296-312.

Barron, D. N. and West, E. (2013). The financial costs of caring in the British labour market: is there a wage penalty for workers in caring occupations? British Journal of Industrial Relations, 51, 104-123

Benoit, C. and Hallgrimsdottir, H. (2011). Valuing care work: Comparative perspectives. University of Toronto Press.

Bischof, D. (2017). New Figure Schemes for Stata: plotplain \&plottig. The Stata Journal, 17, 748-759.

Bolsen, T. and Thornton, J. R. (2014). Overlapping confidence intervals and null hypothesis testing. The Experimental Political Scientist, 4, 12-16.

Budig, M. J., Hodges, M. J. and England, P. (2018). Wages of Nurturant and Reproductive Care Workers: Individual and Job Characteristics, Occupational Closure, and Wage-Equalizing Institutions. Social Problems.

Budig, M. J. and Misra, J. (2010). How care-work employment shapes earnings in crossnational perspective. Interational Labour Review, 149, 441-460.

Chesters, J. and Baxter, J. (2011). Prisoners of love? Job satisfaction in care work. Australian Journal of Social Issues, 46, 49-67.

D'Addio, A. C., Eriksson, T. and Frijters, P. (2007). An analysis of the determinants of job satisfaction when individuals' baseline satisfaction levels may differ. Applied Economics, 39, 2413-2423.

de Bustillo Llorente, R. M. and Macias, E. F. (2005). Job satisfaction as an indicator of the quality of work. The Journal of Socio-Economics, 34, 656-673.

Delhey, J. and Dragolov, G. (2013). Why inequality makes Europeans less happy: The role of distrust, status anxiety, and perceived conflict. European Sociological Review, 30, 151-165.

Duffy, M., Albelda, R. and Hammonds, C. (2013). Counting Care Work: The Empirical and Policy Applications of Care Theory. Social Problems, 60, 145-167.

Dwyer, R. E. (2013). The Care Economy? Gender, Economic Restructuring, and Job Polarization in the US Labor Market. American Sociological Review, 78, 390416.

England, P. (2005). Emerging theories of care work. Annual Review of Sociology, 381399.

England, P., Budig, M. and Folbre, N. (2002). Wages of virtue: The relative pay of care work. Social Problems, 49, 455-473.

England, P., Folbre, N. and Leana, C. (2012). Motivating Care. For Love and Money: Care Provisioning in the United States, Russell Sage Foundation: New York, 2140. 
ESS (2010). European Social Survey Round 5 Data.

Eurofound (2006). Measuring job satisfaction in surveys - comparative analytical report.

Folbre, N. (2001). The invisible heart: Economics and family values. New Press.

Folbre, N. (Ed.) (2012). For Love or Money: Care Provision in the United States. New York, NY: Russell Sage Foundation.

Gerstenblatt, P., Faulkner, M., Lee, A., Doan, L. T. and Travis, D. (2014). Not Babysitting: Work Stress and Well-Being for Family Child Care Providers. Early Childhood Education Journal, 42, 67-75.

Grönlund, A. and Öun, I. (2018). The gender-job satisfaction paradox and the dual-earner society: Are women (still) making work-family trade-offs? Work, 59, 535-545.

Hauret, L. and Williams, D. R. (2017). Cross-National Analysis of Gender Differences in Job Satisfaction. Industrial Relations: A Journal of Economy and Society, 56, 203-235.

Hebson, G., Rubery, J. and Grimshaw, D. (2015). Rethinking job satisfaction in care work: looking beyond the care debates. Work, employment and society, 29, 314330 .

Hochschild, A. (1983). The Managed Heart Berkeley: University of California Press.

Hochschild, A. R. (2012). Global Chains of Care. Review of Women's Studies, 11.

Hochschild, A. R. (2012). The outsourced self: What happens when we pay others to live our lives for us. Macmillan.

Jiang, L. and Probst, T. M. (2017). The rich get richer and the poor get poorer: Countryand state-level income inequality moderates the job insecurity-burnout relationship. Journal of Applied Psychology, 102, 672.

Johnson, E. K. (2015). The business of care: the moral labour of care workers. Sociology of health \& illness, 37, 112-126.

Kevins, A., Horn, A., Jensen, C. and van Kersbergen, K. (2018). Yardsticks of inequality: Preferences for redistribution in advanced democracies. Journal of European Social Policy, 28, 402-418.

Kjeldsen, A. M. and Bøgh Andersen, L. (2013). How Pro-social Motivation Affects Job Satisfaction: An International Analysis of Countries with Different Welfare State Regimes. Scandinavian Political Studies, 36, 153-176.

Layte, R. and Whelan, C. T. (2014). Who Feels Inferior? A Test of the Status Anxiety Hypothesis of Social Inequalities in Health. European Sociological Review, 30, $525-535$.

Lightman, N. (2017). Discounted Labour? Disaggregating Care Work in Comparative Perspective. International Labour Review, 156, 243-267.

Lightman, N. (2018). The Migrant in the Market: Care Penalties and Immigration in Eight Liberal Welfare Regimes. Journal of European Social Policy.

Lowell, B. L., Martin, S. and Stone, R. (2010). Ageing and care giving in the United States: Policy contexts and the immigrant workforce. Journal of Population Ageing, 3, 59-82.

Lutz, H. (2012). Migration and domestic work: A European perspective on a global theme. London: Ashgate Publishing, Ltd.

Magnusson, C. (2008). Gender, Occupational Prestige, and Wages: A Test of Devaluation Theory. European Sociological Review, 25, 87-101. 
Mathieu, J. E., Aguinis, H., Culpepper, S. A. and Chen, G. (2012). Understanding and estimating the power to detect cross-level interaction effects in multilevel modeling. J Appl Psychol, 97, 951-966.

McPhail, R., Patiar, A., Herington, C., Creed, P. and Davidson, M. (2015). Development and initial validation of a hospitality employees' job satisfaction index: Evidence from Australia. International Journal of Contemporary Hospitality Management, 27, 1814-1838.

Mittal, V., Rosen, J. and Leana, C. (2009). A dual-driver model of retention and turnover in the direct care workforce. The Gerontologist, 49, 623-634.

Palmer, E. and Eveline, J. (2012). Sustaining low pay in aged care work. Gender, Work \& Organization, 19, 254-275.

Parreñas, R. S. (2016). New Household Forms, Old Family Values The Formation and Reproduction of the Filipino Transnational Family. Contemporary Asian America: A Multidisciplinary Reader, 157.

Pichler, F. and Wallace, C. (2009). What are the reasons for differences in job satisfaction across Europe? Individual, compositional, and institutional explanations. European Sociological Review, 25, 535-549.

Rose, M. (2003). Good deal, bad deal? Job satisfaction in occupations. Work, employment and society, 17, 503-530.

Schröder, M. (2016). How Income Inequality Influences Life Satisfaction: Hybrid Effects Evidence from the German SOEP. European Sociological Review, 32, 307-320.

Sousa-Poza, A. and Sousa-Poza, A. A. (2000). Taking another look at the gender/jobsatisfaction paradox. Kyklos, 53, 135-152.

Treier, S. and Hillygus, D. S. (2009). The Nature of Political Ideology in the Contemporary Electorate. Public Opinion Quarterly, 73, 679-703.

Tuominen, M. C. (2003). We are not babysitters: Family childcare providers redefine work and care. Rutgers University Press.

Viñas-Bardolet, C., Torrent-Sellens, J. and Guillen-Royo, M. (2018). Knowledge Workers and Job Satisfaction: Evidence from Europe. Journal of the Knowledge Economy.

Wharton, A. S. (1999). The psychosocial consequences of emotional labor. The ANNALS of the American Academy of Political and Social Science, 561, 158-176.

Wilkinson, R. and Pickett, K. (2010). The spirit level: why equality is better for everyone. Penguin UK.

Zou, M. (2015). Gender, work orientations and job satisfaction. Work, employment and society, 29, 3-22. 


\section{Appendix Table 1: Care classification scheme}

\section{Professional Occupations in Care}

Health professionals (except nursing)

Medical doctors

Dentists

Health professionals (not nursing) not elsewhere class

Nursing and midwifery professionals

Teaching professionals

College, university, higher education teaching professionals

Secondary education teaching professionals

Primary and pre-primary education teaching professionals

Primary and pre-primary education teaching professionals

Pre-primary education teaching professionals

Special education teaching professionals

Other teaching professionals

Education methods specialists

Other teaching professionals not elsewhere classified

Social work professionals

Paraprofessional Occupations in Care

Health paraprofessionals (except nursing)

Medical assistants

Dieticians and nutritionists

Optometrists and opticians

Dental assistants

Physiotherapists and related paraprofessionals

Pharmaceutical assistants

Health paraprofessionals except nursing

Nursing and midwifery paraprofessionals

Teaching paraprofessionals

Primary education teaching paraprofessionals

Pre-primary education teaching paraprofessionals

Special education teaching paraprofessionals

Other teaching paraprofessionals

Social work paraprofessionals

Non-Professional (Service) Occupations in Care

Housekeeping, restaurant service workers

Housekeepers and related workers

Cooks

Waiters, waitresses and bartenders
ISCO-88 Code

2220

2221

2222

2229

2230

2300

2310

2320

2330

2331

2332

2340

2350

2351

2359

2446

ISCO-88 Code

3220

3221

3223

3224

3225

3226

3228

3229

3230-3232

3300

3310

3320

3330

3340

3460

\section{ISCO-88 Code}

5120

5121

5122

5123 
Personal care and related workers $\quad 5130$

Child-care workers 5131

Institution-based personal care workers 5132

Home-based personal care workers 5133

Personal care, related workers not elsewhere classified 5139

Hairdressers, barbers, beauticians, related workers 5141

Companions and valets 5142

Undertakers and embalmers 5143

Other personal service workers not elsewhere classified $\quad 5149$ 
Appendix Table 2: Weighted descriptive statistics

\begin{tabular}{lcccc}
\hline & Mean & $\begin{array}{c}\text { Standard } \\
\text { Deviation }\end{array}$ & $\begin{array}{c}\text { Minimum } \\
\text { Value }\end{array}$ & $\begin{array}{c}\text { Maximum } \\
\text { Value }\end{array}$ \\
\hline Job satisfaction & -.0040878 & .8454073 & -3.385212 & 2.539296 \\
Support & 3.1813 & .8794211 & 1 & 4 \\
Advancement & 3.188378 & 1.172846 & 1 & 5 \\
Pay & 2.844758 & 1.131347 & 1 & 5 \\
Variety of Tasks & 3.024618 & .9599935 & 1 & 4 \\
Job security & 2.868163 & 1.058122 & 1 & 4 \\
Job enjoyment & 2.904294 & 1.258052 & 1 & 5 \\
Overall Satisfaction & 7.443461 & 1.884787 & 0 & 10 \\
Care Work & .2292251 & .4203555 & 0 & 1 \\
Professionalism & .961756 & .7417647 & 0 & 2 \\
Immigrant & .1053776 & .3070549 & 0 & 1 \\
Self-identified & .0479241 & .2136164 & 0 & 1 \\
minority & & & & \\
Education & 2.416751 & .9420857 & 1 & 4 \\
Income decile & 6.471608 & 2.484665 & 1 & 10 \\
Household size & 2.926758 & 1.322784 & 1 & 11 \\
Male & .5138469 & .4998334 & 0 & 1 \\
Age & 42.4802 & 11.38242 & 18 & 70 \\
Trade union member & .2438793 & .4294424 & 0 & 1 \\
Public sector & .332091 & .4709872 & 0 & 1 \\
employee & & & & \\
Supervisor & .3506466 & .4771965 & 0 & 1 \\
Self employed & .0000429 & .0065528 & 0 & 1 \\
Fixed-term contract & .1419575 & .3490242 & 0 & 1 \\
Part-time employed & .2007838 & .4006068 & 0 & 1 \\
Married & .5501336 & .4975054 & 0 & 1 \\
Gini coefficient & 29.93009 & 2.984056 & 23.6 & 36.9 \\
Unemployment rate & 9.374948 & 4.332335 & 3.5 & 20.1 \\
GDP per capita & 10.54303 & .2790234 & 9.389604 & 11.36281 \\
(natural log) & & & & \\
\hline & & & & \\
\hline & & & 0 & \\
& & & & 0 \\
\hline
\end{tabular}


Appendix Table 3: Individual-level model predicting job satisfaction, using generalized least squares fixed-effects regressions

\begin{tabular}{lcccc}
\hline & Model 1 & Model 2 & Model 3 & Model 4 \\
\hline Care worker & $0.136^{* * *}$ & 0.0464 & $0.0823^{*}$ & $0.0786^{*}$ \\
& $(0.019)$ & $(0.032)$ & $(0.033)$ & $(0.034)$
\end{tabular}

Professionalism: baseline -

Professional

Non-professional

Paraprofessional

Care worker \# Non-

professional

Care worker \#

paraprofessional

$\begin{array}{cccc}-0.429^{* * *} & -0.478^{* * *} & -0.395^{* * *} & -0.335^{* * *} \\ (0.021) & (0.025) & (0.029) & (0.029) \\ -0.220^{* * *} & -0.251^{* * *} & -0.204^{* * *} & -0.152^{* * *} \\ (0.020) & (0.022) & (0.025) & (0.025) \\ & 0.167^{* * *} & 0.148^{* *} & 0.127^{* *} \\ & (0.046) & (0.046) & (0.046) \\ & 0.105^{*} & 0.0870^{+} & 0.0312 \\ & (0.047) & (0.047) & (0.047)\end{array}$

\section{Demographic Controls}

Male

Self-identified minority

Immigrant

Married

Age

Age \# Age

Education: baseline - Less

than secondary

Upper secondary

Post-secondary non-tertiary

Tertiary

Income decile

Household size

$\begin{array}{cc}-0.0344 & -0.0475^{+} \\ (0.026) & (0.026) \\ -0.0497^{+} & -0.0778^{* *} \\ (0.029) & (0.028) \\ -0.0692^{*} & -0.0999^{* *} \\ (0.034) & (0.034) \\ 0.0454^{* * *} & 0.0408^{* * *} \\ (0.004) & (0.004) \\ -0.00402 & -0.00575 \\ (0.007) & (0.007)\end{array}$

\section{Labor Market Controls}

Trade union member

0.0215

$(0.020)$

Public sector employee

Supervisor

(0.018) $0.208^{* * *}$ (0.018) 
Self employed

0.315

$(0.439)$

Fixed-term contract

$-0.0791^{* *}$

Part-time employed

$(0.024)$

$0.0694^{* *}$

\begin{tabular}{lcccc} 
Constant & $0.188^{* * *}$ & $0.217^{* * *}$ & $0.273^{*}$ & $(0.023)$ \\
& $(0.016)$ & $(0.018)$ & $(0.107)$ & $(0.109)$ \\
\hline Observations & 9917 & 9917 & 9917 & 9917 \\
Countries & 18 & 18 & 18 & 18 \\
\hline
\end{tabular}

Note: Cells contain generalized least squares fixed-effects regression coefficients, with standard errors in parentheses.

${ }^{+} p<0.10,{ }^{*} p<0.05,{ }^{* *} p<0.01,{ }^{* * *} p<0.001$ 
Appendix Table 4: Full model predicting job satisfaction, using maximum likelihood regressions

\begin{tabular}{|c|c|c|c|c|}
\hline & Model 1 & Model 2 & Model 3 & Model 4 \\
\hline Care worker & $\begin{array}{l}0.0781^{+} \\
(0.044)\end{array}$ & $\begin{array}{l}0.0892 \\
(0.057)\end{array}$ & $\begin{array}{l}0.0890 \\
(0.057)\end{array}$ & $\begin{array}{l}0.0893 \\
(0.057)\end{array}$ \\
\hline \multicolumn{5}{|l|}{$\begin{array}{l}\text { Professionalism: baseline - } \\
\text { Professional }\end{array}$} \\
\hline Non-professional & $\begin{array}{c}-0.499^{* * *} \\
(0.050)\end{array}$ & $\begin{array}{c}-0.369^{* * *} \\
(0.043)\end{array}$ & $\begin{array}{c}-0.369^{* * *} \\
(0.043)\end{array}$ & $\begin{array}{c}-0.369^{* * *} \\
(0.043)\end{array}$ \\
\hline Paraprofessional & $\begin{array}{l}-0.233^{* * *} \\
(0.018)\end{array}$ & $\begin{array}{l}-0.141^{* * *} \\
(0.030)\end{array}$ & $\begin{array}{l}-0.141^{* * *} \\
(0.030)\end{array}$ & $\begin{array}{l}-0.142^{* * *} \\
(0.029)\end{array}$ \\
\hline Care worker \# Non-professional & $\begin{array}{l}0.238^{* * *} \\
(0.060)\end{array}$ & $\begin{array}{c}0.188^{* * *} \\
(0.052)\end{array}$ & $\begin{array}{c}0.188^{* * *} \\
(0.052)\end{array}$ & $\begin{array}{l}0.185^{* * *} \\
(0.053)\end{array}$ \\
\hline Care worker \# paraprofessional & $\begin{array}{c}0.102 \\
(0.106)\end{array}$ & $\begin{array}{l}0.0104 \\
(0.106)\end{array}$ & $\begin{array}{l}0.0104 \\
(0.107)\end{array}$ & $\begin{array}{c}0.00918 \\
(0.107)\end{array}$ \\
\hline Gini coefficient (centred) & $\begin{array}{r}-0.0212^{+} \\
(0.012)\end{array}$ & $\begin{array}{c}-0.0223^{+} \\
(0.013)\end{array}$ & $\begin{array}{c}0.00428 \\
(0.018)\end{array}$ & $\begin{array}{c}-0.000634 \\
(0.010)\end{array}$ \\
\hline Care worker \# Gini coefficient & $\begin{array}{l}0.0217^{*} \\
(0.010)\end{array}$ & $\begin{array}{c}0.0221^{* *} \\
(0.008)\end{array}$ & $\begin{array}{l}0.0223^{* *} \\
(0.008)\end{array}$ & $\begin{array}{l}0.0218^{* *} \\
(0.008)\end{array}$ \\
\hline Non-professional \# Gini coefficient & $\begin{array}{c}0.000129 \\
(0.010)\end{array}$ & $\begin{array}{c}0.00170 \\
(0.010)\end{array}$ & $\begin{array}{l}0.00183 \\
(0.010)\end{array}$ & $\begin{array}{c}0.00191 \\
(0.011)\end{array}$ \\
\hline Paraprofessional \# Gini coefficient & $\begin{array}{c}-0.00142 \\
(0.007)\end{array}$ & $\begin{array}{c}-0.00134 \\
(0.006)\end{array}$ & $\begin{array}{c}-0.00116 \\
(0.006)\end{array}$ & $\begin{array}{c}-0.00106 \\
(0.006)\end{array}$ \\
\hline Care worker \# Non-professional \# & -0.0107 & -0.0103 & -0.0106 & -0.0102 \\
\hline Gini coefficient & $(0.013)$ & $(0.011)$ & $(0.011)$ & $(0.011)$ \\
\hline $\begin{array}{l}\text { Care worker \# Paraprofessional \# Gini } \\
\text { coefficient }\end{array}$ & $\begin{array}{l}0.00803 \\
(0.009)\end{array}$ & $\begin{array}{c}0.00608 \\
(0.009)\end{array}$ & $\begin{array}{r}0.00583 \\
(0.009)\end{array}$ & $\begin{array}{c}0.00652 \\
(0.009)\end{array}$ \\
\hline \multicolumn{5}{|l|}{ Demographic Controls } \\
\hline Male & & $\begin{array}{l}0.0257 \\
(0.023)\end{array}$ & $\begin{array}{l}0.0253 \\
(0.023)\end{array}$ & $\begin{array}{l}0.0247 \\
(0.023)\end{array}$ \\
\hline Self-identified minority & & $\begin{array}{c}-0.0172 \\
(0.036)\end{array}$ & $\begin{array}{l}-0.0175 \\
(0.036)\end{array}$ & $\begin{array}{r}-0.0167 \\
(0.036)\end{array}$ \\
\hline Immigrant & & $\begin{array}{c}-0.00527 \\
(0.030)\end{array}$ & $\begin{array}{c}-0.00557 \\
(0.030)\end{array}$ & $\begin{array}{c}-0.00420 \\
(0.031)\end{array}$ \\
\hline Married & & $\begin{array}{l}0.0722^{+} \\
(0.039)\end{array}$ & $\begin{array}{l}0.0716^{+} \\
(0.039)\end{array}$ & $\begin{array}{l}0.0713^{+} \\
(0.039)\end{array}$ \\
\hline Age & & $\begin{array}{c}-0.0269^{* * *} \\
(0.004)\end{array}$ & $\begin{array}{c}-0.0269^{* * *} \\
(0.004)\end{array}$ & $\begin{array}{c}-0.0270^{* * *} \\
(0.004)\end{array}$ \\
\hline Age \# Age & & $\begin{array}{l}0.000302^{* * *} \\
\quad(0.000)\end{array}$ & $\begin{array}{l}0.000301^{* * *} \\
(0.000)\end{array}$ & $\begin{array}{l}0.000303^{* * *} \\
(0.000)\end{array}$ \\
\hline $\begin{array}{l}\text { Education: baseline - Less than } \\
\text { secondary }\end{array}$ & & & & \\
\hline Upper secondary & & $\begin{array}{c}-0.0815^{* * *} \\
(0.024)\end{array}$ & $\begin{array}{l}-0.0820^{* * *} \\
(0.025)\end{array}$ & $\begin{array}{c}-0.0780^{* *} \\
(0.025)\end{array}$ \\
\hline Post-secondary non-tertiary & & $\begin{array}{c}-0.0981^{* *} \\
(0.032)\end{array}$ & $\begin{array}{c}-0.0980^{* *} \\
(0.032)\end{array}$ & $\begin{array}{c}-0.0944^{* *} \\
(0.032)\end{array}$ \\
\hline Tertiary & & $\begin{array}{c}-0.172^{* * *} \\
(0.030)\end{array}$ & $\begin{array}{c}-0.171^{* * *} \\
(0.031)\end{array}$ & $\begin{array}{c}-0.169^{* * *} \\
(0.031)\end{array}$ \\
\hline
\end{tabular}


Income decile

$\begin{array}{ccc}0.0360^{* * *} & 0.0360^{* * *} & 0.0359^{* * *} \\ (0.010) & (0.010) & (0.010) \\ -0.00574 & -0.00561 & -0.00523 \\ (0.007) & (0.007) & (0.007)\end{array}$

\section{Labor Market Controls}

Trade union member

$\begin{array}{lll}-0.0176 & -0.0165 & -0.0149\end{array}$

Public sector employee

$\begin{array}{lll}(0.057) & (0.057) & (0.054)\end{array}$

$0.144^{* * *} \quad 0.144^{* * *} \quad 0.144^{* * *}$

Supervisor

$\begin{array}{lll}(0.035) & (0.035) & (0.035)\end{array}$

$0.239^{* * *} \quad 0.239^{* * *} \quad 0.239^{* * *}$

Self employed

$\begin{array}{lll}(0.019) & (0.019) & (0.019)\end{array}$

$0.204^{* * *} \quad 0.223^{* * *} \quad 0.205^{* * *}$

$\begin{array}{lll}(0.037) & (0.046) & (0.056)\end{array}$

$\begin{array}{lll}-0.0317 & -0.0314 & -0.0319\end{array}$

Fixed-term contract

$\begin{array}{lll}(0.059) & (0.059) & (0.059)\end{array}$

Part-time employed

$0.105^{* * *} \quad 0.104^{* * *} \quad 0.103^{* * *}$

$\begin{array}{lll}(0.017) & (0.017) & (0.018)\end{array}$

\section{Country Controls}

Unemployment rate

$-0.0320^{*} \quad 0.00553$

(0.014) (0.007)

GDP (natural $\log$ )

$0.469^{* * *}$

\begin{tabular}{lcccc} 
& & & & \\
Constant & $0.177^{* *}$ & $0.350^{* * *}$ & $0.666^{* * *}$ & $-4.594^{* * *}$ \\
& $(0.057)$ & $(0.075)$ & $(0.129)$ & $(0.813)$ \\
\hline Variances & & & & \\
Country & $-1.412^{* * *}$ & $-1.467^{* * *}$ & $-1.603^{* * *}$ & $-2.599^{* * *}$ \\
& $(0.193)$ & $(0.202)$ & $(0.189)$ & $(0.253)$ \\
Residual & & & & \\
& $-0.216^{* * *}$ & $-0.238^{* * *}$ & $-0.238^{* * *}$ & $-0.238^{* * *}$ \\
Observations & $(0.019)$ & $(0.019)$ & $(0.019)$ & $(0.019)$ \\
Countries & 9917 & 9917 & 9917 & 9917 \\
\hline
\end{tabular}

Note: Cells contain maximum likelihood regression coefficients, with standard errors in parentheses. All models incorporate survey weights.

${ }^{+} p<0.10,{ }^{*} p<0.05,{ }^{* *} p<0.01,{ }^{* * *} p<0.001$ 
Appendix Table 5: Robustness checks, using ordinary least squares regression (Model 1) and maximum likelihood regressions (Models 2 and 3)

\begin{tabular}{|c|c|c|c|}
\hline & Model 1 & Model 2 & Model 3 \\
\hline Care worker & $\begin{array}{l}0.108^{*} \\
(0.053)\end{array}$ & $\begin{array}{l}0.0893 \\
(0.057)\end{array}$ & $\begin{array}{l}0.0852 \\
(0.058)\end{array}$ \\
\hline Professionalism: baseline - Professional & & & \\
\hline Non-professional & $\begin{array}{c}-0.365^{* * *} \\
(0.047)\end{array}$ & $\begin{array}{c}-0.369^{* * *} \\
(0.043)\end{array}$ & $\begin{array}{c}-0.383^{* * *} \\
(0.034)\end{array}$ \\
\hline Paraprofessional & $\begin{array}{c}-0.139^{* * *} \\
(0.039)\end{array}$ & $\begin{array}{c}-0.142^{* * *} \\
(0.029)\end{array}$ & $\begin{array}{c}-0.153^{* * *} \\
(0.034)\end{array}$ \\
\hline Care worker \# Non-professional & $\begin{array}{c}0.181^{*} \\
(0.072)\end{array}$ & $\begin{array}{c}0.185^{* * *} \\
(0.053)\end{array}$ & $\begin{array}{c}0.176^{* * *} \\
(0.050)\end{array}$ \\
\hline Care worker \# Paraprofessional & $\begin{array}{c}0.00843 \\
(0.068)\end{array}$ & $\begin{array}{c}0.00918 \\
(0.107)\end{array}$ & $\begin{array}{l}0.0146 \\
(0.108)\end{array}$ \\
\hline Gini coefficient (centred) & & $\begin{array}{c}-0.000634 \\
(0.010)\end{array}$ & $\begin{array}{c}0.00528 \\
(0.010)\end{array}$ \\
\hline Care worker \# Gini coefficient & & $\begin{array}{c}0.0218^{* *} \\
(0.008)\end{array}$ & $\begin{array}{l}0.0182^{*} \\
(0.007)\end{array}$ \\
\hline Non-professional \# Gini coefficient & & $\begin{array}{c}0.00191 \\
(0.011)\end{array}$ & $\begin{array}{c}-0.00549 \\
(0.009)\end{array}$ \\
\hline Paraprofessional \# Gini coefficient & & $\begin{array}{c}-0.00106 \\
(0.006)\end{array}$ & $\begin{array}{c}-0.00622 \\
(0.007)\end{array}$ \\
\hline Care worker \# Non-professional \# Gini coefficient & & $\begin{array}{r}-0.0102 \\
(0.011)\end{array}$ & $\begin{array}{c}-0.00930 \\
(0.010)\end{array}$ \\
\hline Care worker \# Paraprofessional \# Gini coefficient & & $\begin{array}{c}0.00652 \\
(0.009)\end{array}$ & $\begin{array}{c}0.00830 \\
(0.010)\end{array}$ \\
\hline \multicolumn{4}{|l|}{ Demographic Controls } \\
\hline Male & $\begin{array}{l}0.0263 \\
(0.029)\end{array}$ & $\begin{array}{l}0.0247 \\
(0.023)\end{array}$ & $\begin{array}{l}0.0222 \\
(0.022)\end{array}$ \\
\hline Self-identified minority & $\begin{array}{r}-0.0152 \\
(0.067)\end{array}$ & $\begin{array}{r}-0.0167 \\
(0.036)\end{array}$ & $\begin{array}{l}-0.0176 \\
(0.036)\end{array}$ \\
\hline Immigrant & $\begin{array}{c}-0.00711 \\
(0.044)\end{array}$ & $\begin{array}{c}-0.00420 \\
(0.031)\end{array}$ & $\begin{array}{c}-0.000488 \\
(0.030)\end{array}$ \\
\hline Married & $\begin{array}{l}0.0711^{*} \\
(0.031)\end{array}$ & $\begin{array}{l}0.0713^{+} \\
(0.039)\end{array}$ & $\begin{array}{l}0.0707^{+} \\
(0.040)\end{array}$ \\
\hline Age & $\begin{array}{c}-0.0269^{* *} \\
(0.008)\end{array}$ & $\begin{array}{c}-0.0270^{* * *} \\
(0.004)\end{array}$ & $\begin{array}{c}-0.0267^{* * *} \\
(0.004)\end{array}$ \\
\hline Age \# Age & $\begin{array}{c}0.000302^{* *} \\
(0.000)\end{array}$ & $\begin{array}{c}0.000303^{* * *} \\
(0.000)\end{array}$ & $\begin{array}{c}0.000300^{* * *} \\
(0.000)\end{array}$ \\
\hline Education: baseline - Less than secondary & & & \\
\hline Upper secondary & $\begin{array}{r}-0.0765^{+} \\
(0.041)\end{array}$ & $\begin{array}{c}-0.0780^{* *} \\
(0.025)\end{array}$ & $\begin{array}{c}-0.0764^{* *} \\
(0.026)\end{array}$ \\
\hline Post-secondary non-tertiary & $\begin{array}{c}-0.0944^{*} \\
(0.043)\end{array}$ & $\begin{array}{c}-0.0944^{* *} \\
(0.032)\end{array}$ & $\begin{array}{c}-0.0966^{* *} \\
(0.031)\end{array}$ \\
\hline Tertiary & $\begin{array}{c}-0.164^{* *} \\
(0.054)\end{array}$ & $\begin{array}{c}-0.169^{* * *} \\
(0.031)\end{array}$ & $\begin{array}{c}-0.179^{* * *} \\
(0.034)\end{array}$ \\
\hline Income decile & $\begin{array}{c}0.0360^{* * * *} \\
(0.006)\end{array}$ & $\begin{array}{c}0.0359^{* * *} \\
(0.010)\end{array}$ & $\begin{array}{c}0.0363^{* * *} \\
(0.010)\end{array}$ \\
\hline
\end{tabular}


Household size

$$
\begin{array}{ccc}
-0.00519 & -0.00523 & -0.00507 \\
(0.012) & (0.007) & (0.007)
\end{array}
$$

\section{Labor Market Controls}

Trade union member

$\begin{array}{ccc}-0.0177 & -0.0149 & -0.0144 \\ (0.034) & (0.054) & (0.054) \\ 0.144^{* * *} & 0.144^{* * *} & 0.142^{* * *} \\ (0.031) & (0.035) & (0.035) \\ 0.239^{* * *} & 0.239^{* * *} & 0.238^{* * *} \\ (0.028) & (0.019) & (0.019) \\ 0.266 & 0.205^{* * *} & 0.202^{* * *} \\ (0.283) & (0.056) & (0.056) \\ -0.0313 & -0.0319 & -0.0297 \\ (0.039) & (0.059) & (0.059) \\ 0.103^{* *} & 0.103^{* * *} & 0.100^{* * *} \\ (0.036) & (0.018) & (0.018)\end{array}$

\section{Country Controls}

Unemployment rate

$0.00553 \quad 0.00517$

GDP (natural log)

$\begin{array}{ll}(0.007) & (0.007) \\ 0.469^{* * *} & 0.476^{* * *} \\ (0.072) & (0.073)\end{array}$

Country: baseline - Austria

Belgium

$0.131^{*}$

(0.052)

$0.322^{* * *}$

$(0.050)$

$-0.518^{* * *}$

$(0.048)$

0.0253

$(0.045)$

$0.259^{* * *}$

(0.056)

$-0.0478$

$(0.049)$

$-0.125^{*}$

$(0.052)$

0.0644

$(0.053)$

$-0.122^{*}$

$(0.051)$

$-0.0749$

(0.049)

$-0.440^{* * *}$

Croatia

(0.059)

$-0.333^{* * *}$

Lithuania

(0.068)

0.0231

(0.051)

Norway

$0.308^{* * * *}$ 


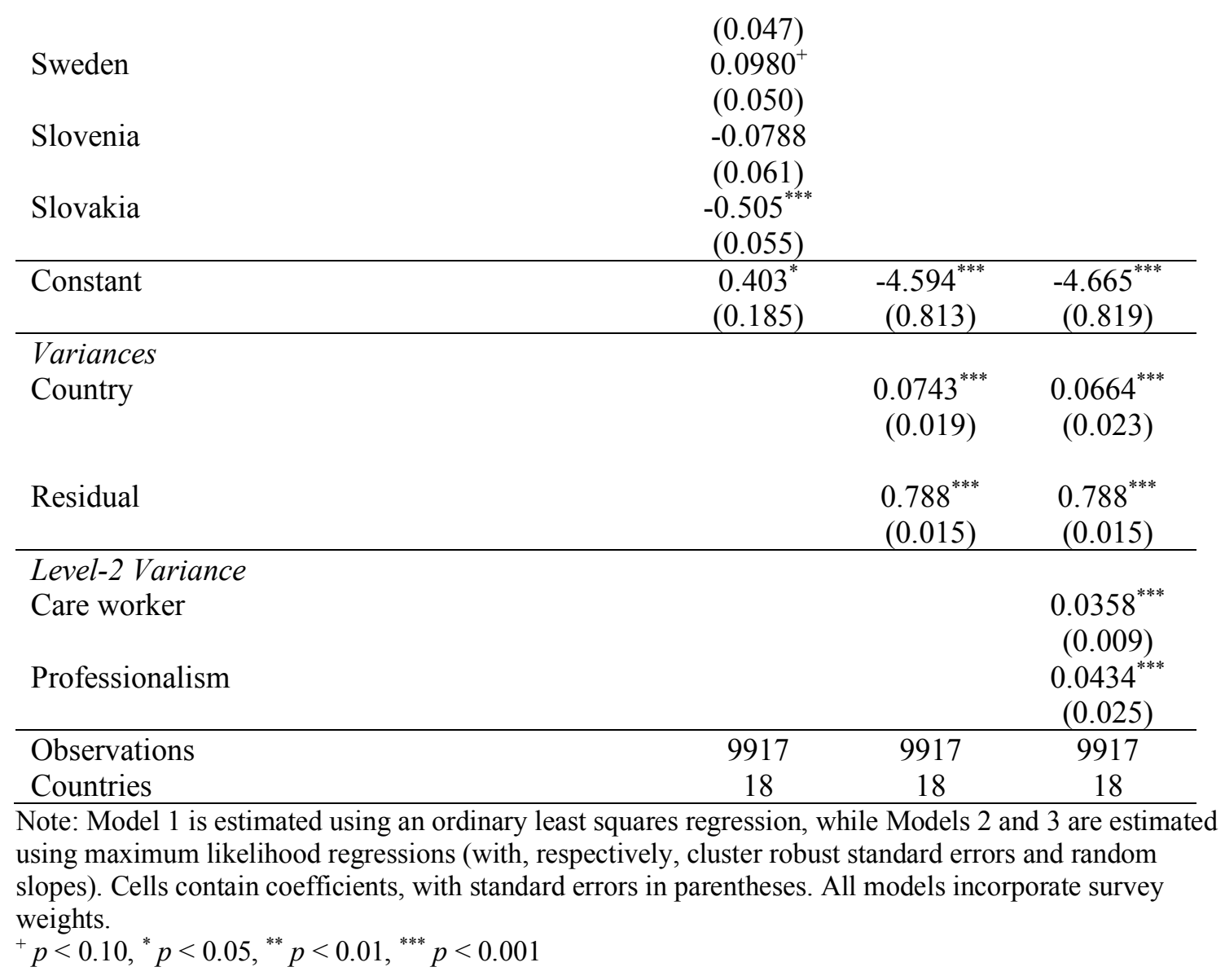

